\title{
Fluorinated graphene nanoribbons from unzipped single-walled carbon nanotubes for ultrahigh energy density lithium-fluorinated carbon batteries
}

\author{
Cong Peng, Lingchen Kong, Yu Li ${ }^{*}$, Haoyu Fu, Lidong Sun, Yiyu Feng and Wei Feng*
}

\begin{abstract}
Lithium-fluorinated carbon $\left(\mathrm{Li}-\mathrm{CF}_{x}\right)$ batteries have become one of the most widely applied power sources for high energy density applications because of the advantages provided by the $\mathrm{CF}_{x}$ cathode. Moreover, the large gap between the practical and theoretical potentials alongside the stoichiometric limit of commercial graphite fluorides indicates the potential for further energy improvement. Herein, monolayer fluorinated graphene nanoribbons (F-GNRs) were fabricated by unzipping single-walled carbon nanotubes (SWCNTs) using pure $\mathrm{F}_{2}$ gas at high temperature, which delivered an unprecedented energy density of $2738.45 \mathrm{~W} \mathrm{~h} \mathrm{~kg}^{-1}$ due to the combined effect of a high fluorination degree and discharge plateau, realized by the abundant edges and destroyed periodic structure, respectively. Furthermore, at a high fluorination temperature, the theoretical calculation confirmed a zigzag pathway of fluorine atoms that were adsorbed outside of the SWCNTs and hence initiated the spontaneous process of unzipping SWCNTs to form the monolayer F-GNRs. The controllable fluorination of SWCNTs provided a feasible approach for preparing $\mathrm{CF}_{x}$ compounds for different applications, especially for ultrahigh-energy-density cathodes.
\end{abstract}

Keywords: fluorinated graphene nanoribbons, unzipped, singlewalled carbon nanotubes, ultrahigh energy density, lithiumfluorinated carbon batteries

\section{INTRODUCTION}

Although rapid development of rechargeable lithium ion batteries has occurred in the past decade, lithium primary batteries are still irreplaceable in special fields that require long storage lifetimes, high energy densities, and wide operational temperature ranges, such as the aerospace, and medical devices $[1,2]$. Among various solid cathode materials, fluorinated carbon $\left(\mathrm{CF}_{x}\right)$ has attracted unprecedent attention due to their high theoretical energy density, which is much higher than that of lithium ion batteries $\left(\sim 500 \mathrm{~W} \mathrm{~h} \mathrm{~kg}^{-1}\right)$ [3]. To fill this short-term technology gap for producing batteries with higher energy densities, several types of nonaqueous metal-gas batteries have been explored to meet growing demands, such as $\mathrm{Li}-\mathrm{O}_{2}[4], \mathrm{Na}-\mathrm{O}_{2}[5], \mathrm{K}^{-} \mathrm{O}_{2}[6], \mathrm{Li}^{-} \mathrm{CO}_{2}[7,8]$, Li$\mathrm{NF}_{3}$ [9], and $\mathrm{Li}_{-} \mathrm{SF}_{6}$ [10-12]. However, the gas-to-solid conversion reaction involves a solution-mediated electrochemical process that induces complex thermodynamics, kinetics, and transport considerations, and it remains a challenge to achieve the potential energy densities and realize practical applications for these systems. On the other hand, several new types of solid cathode materials with theoretically high capacities have also been suggested, including sulfur $[13,14]$ and organic compounds [15-17]. However, these systems present accompanying issues such as low operational potentials, selfdischarge, and large special electrolyte consumption for extra capacity.

Stoichiometric carbon monofluoride $\left(\mathrm{CF}_{1}\right)$ has been applied in commercial lithium primary batteries with high energy densities, and its overall theoretical energy density is $2119 \mathrm{~W} \mathrm{~h} \mathrm{~kg}^{-1}$ based on the operational potential and specific capacity $\left(865 \mathrm{~mA} \mathrm{~h} \mathrm{~g}^{-1}\right)$ [18]. Recently, our group $[19,20]$ substituted hard carbon derived from biomass for conventional graphite as the raw carbonaceous materials of $\mathrm{CF}_{x}$, and the corresponding pro-

School of Materials Science and Engineering; Tianjin Key Laboratory of Composite and Functional Materials; Key Laboratory of Advanced Ceramics and Machining Technology, Ministry of Education, Tianjin University, Tianjin 300354, China

* Corresponding authors (emails: weifeng@tju.edu.cn (Feng W); liyuajde@tju.edu.cn (Li Y)) 
ducts delivered energy densities of approximately $2600 \mathrm{~W} \mathrm{~h} \mathrm{~kg}^{-1}$, higher than the theoretical value of $\mathrm{CF}_{1}$, thanks to the enhanced electrochemical activity of the $\mathrm{C}-\mathrm{F}$ bond caused by periodic structure destruction. In addition, Ahmad et al. [21,22] also demonstrated the extra capacity of $\mathrm{CF}_{x}$, derived from carbon nanodiscs and few-walled carbon nanotubes, due to the further consumption of $\mathrm{Li}^{+}$by the carbon host after electrochemical de-fluorination. Therefore, potential remains for further enhancing the energy density of $\mathrm{CF}_{x}$ by considering the huge gap between the operational potential and the thermoneutral potential at $4.57 \mathrm{~V}$, alongside the maneuverbility of its stoichiometry [23].

Among numerous types of $\mathrm{CF}_{x}$ compounds, twodimensional (2D) fluorinated graphene (FG) is the most interesting because of its potential rate capability achieved by shortening $\mathrm{Li}^{+}$diffusion path [24]. With the aid of its semi-ionic C-F bond, FG exhibited a high operational potential $\left(>3.0 \mathrm{~V} v s . \mathrm{Li}^{-} \mathrm{Li}^{+}\right)$and excellent power density $\left(\sim 21 \mathrm{~kW} \mathrm{~kg}^{-1}\right) \quad[25,26]$. Nevertheless, the analogous structure of fluorographene and carbon monofluoride prohibits the further improvement of the energy density. Graphene nanoribbons (GNRs) are strips of graphene with a high length-to-width ratio and straight edges, which gradually transform from semiconductors to semimetals as their width increases and represent a particularly versatile variety [27]. As expected, it was theoretically demonstrated that fluorinated GNRs (F-GNRs) exhibited several unique electronic and magnetic properties [28,29]. However, the fluorination of unzipped multi-walled carbon nanotubes (MWCNTs) using a mixture of $\mathrm{F}_{2}$ and $\mathrm{H}_{2}$ has been the only reported method for F-GNRs, which exhibited a relatively low fluorine content [30].

Inspired by the approach of synthesizing GNRs by unzipping MWCNTs in strong oxidative sulfuric acid [31], $\mathrm{F}_{2}$ gas was employed as the oxidant to unzip singlewalled carbon nanotubes (SWCNTs) and form corresponding F-GNRs. It was determined that the SWCNTs were unzipped when the fluorination temperature was higher than $300^{\circ} \mathrm{C}$. The elemental and structural analysis indicated that the stoichiometric value of the F-GNRs was approximately 1.21 due to the presence of secondary alkyl fluoride $\left(-\mathrm{CF}_{2}\right)$ groups at the abundant edges. The firstprinciples calculation demonstrated spontaneous unzipping of the SWCNTs along a zigzag path. As the cathode of Li- $\mathrm{CF}_{x}$ batteries, FGNRs delivered energy densities higher than $2738.45 \mathrm{~W} \mathrm{~h} \mathrm{~kg}^{-1}$, demonstrating their promising application in fields requiring power sources with ultrahigh energy densities.

\section{EXPERIMENTAL SECTION}

\section{Fluorination of SWCNTs}

The high-purity SWCNTs were purchased from Nanjing XFNANO Materials Tech Co., Ltd with the average diameter about 1-2 nm. Before the fluoridation, SWCNTs were suspended in $30 \% \mathrm{HCl}$ for several hours to remove the remained catalyst and amorphous carbon. Then the solution was centrifuged and the remaining solid material was refined by de-ionized water until the filtrate became neutral. The solid obtained after filtration was vacuumdried overnight at $60^{\circ} \mathrm{C}$.

The fluorination of purified SWCNTs was carried out through a homemade Monel reactor. Typically, $200 \mathrm{mg}$ of purified powder was sealed in the reactor and pumped down to 0.400 Torr. Then, the reactor was filled with pure $\mathrm{F}_{2}$ gas to ambient pressure and then heated to a certain temperature ranged from 200 to $400^{\circ} \mathrm{C}$ with temperature intervals about $50^{\circ} \mathrm{C}$. The fluorination reaction lasted for $4 \mathrm{~h}$. The fluorinated products were labeled as $\mathrm{CF}_{x}-\mathrm{a}, \mathrm{CF}_{x^{-}}$ b, $\mathrm{CF}_{x}-\mathrm{c}, \mathrm{CF}_{x}-\mathrm{d}$ and $\mathrm{CF}_{x}$-e with the increase of fluorination temperature, respectively. After the reaction, $\mathrm{N}_{2}$ gas flow was filled into the reactor to push out the reactant gas, and the products were allowed to cool in $\mathrm{N}_{2}$ until ambient temperature before being taken out from the reactor.

\section{Materials characterization}

$\mathrm{X}$-ray diffraction (XRD) patterns were measured on an Xray area detector $(\mathrm{D} / \max -25$, Rigaku) with $\mathrm{Cu} \mathrm{Ka}$ radiation $(\lambda=1.5406 \AA, 40 \mathrm{kV}$ and $40 \mathrm{~mA})$. Fourier transform infrared (FTIR) spectra were recorded by the attenuated total reflectance mode in the range of $3000-400 \mathrm{~cm}^{-1}$ on an infrared spectrophotometer (FT/IR$300 \mathrm{E}$, JASCO Corporation). Raman spectra were recorded at room temperature with a charge-coupled device multichannel detector (DXR Microscope). The radiation source was a 523-nm Argon laser line and the laser power was tuned to $10 \mathrm{~mW}$ in order not to decompose the material. X-ray photoelectron spectroscopy (XPS) analysis was performed using a spectrometer (PERKIN ELMZR PHI 3056) with an $\mathrm{Al}$ anode source operated at $15 \mathrm{kV}$ to analyze the chemical composition of the materials, wherein the binding energy was calibrated taking $\mathrm{C} 1 \mathrm{~s}$ at $284.06 \mathrm{eV}$. Transmission electron microscopy (TEM, S-4800, Hitachi) was applied for the structural characterization for the products. Atomic force microscopy (AFM) was performed (Bruker, Dimension Icon) to characterize the size and height of products spin-coated on $\mathrm{SiO}_{2}$ substrate. 


\section{Theoretical calculations}

All of the calculations were carried out using density functional theory (DFT), which was implemented in the Vienna Ab initio Software Package (VASP) code using the Perdew-Burke-Ernzerhof (PBE) generalized gradient approximation and the projected augmented wave (PAW) method [32,33]. The cutoff energy for the planewave basis set was set to $400 \mathrm{eV}$. The Brillouin zone of the surface unit cell was sampled by Monkhorst-Pack (MP) grids to optimize the structure of the SWCNTs [34]. The SWCNTs were measured by $3 \times 3 \times 3$ Monkhorst-Pack grids. The convergence criteria for the electronic selfconsistent iteration and force were set to $10^{-5} \mathrm{eV}$ and $0.01 \mathrm{eV} \AA^{-1}$, respectively. The free energies of the adsorbate and transition states at temperature $T$ were estimated according to the harmonic approximation, and the entropy $S$ was evaluated using the following equation:

$S(T)=k_{\mathrm{B}} \sum_{i}^{\text {harmDOF }}\left[\frac{\varepsilon_{i}}{k_{\mathrm{B}} T\left(e^{\varepsilon_{i} / k_{\mathrm{B}} T}-1\right)}-\ln \left(1-e^{-\varepsilon_{i} / k_{\mathrm{B}} T}\right)\right]$,

where $k_{\mathrm{B}}$ is the Boltzmann constant and DOF is the number of harmonic energies $\left(\varepsilon_{i}\right)$ used in the summation, denoted as the degree of freedom. Meanwhile, the free energies of the gas phase species $\left(G_{\mathrm{g}}\right)$ were corrected as:

$G_{\mathrm{g}}(T)=E_{\text {elec }}+E_{\mathrm{ZPE}}+\int C_{\mathrm{p}} \mathrm{d} T-T S(T)$,

where $C_{\mathrm{p}}$ is the gas-phase heat capacity as a function of temperature derived from the Shomate equations and the corresponding parameters in the equation were obtained from the National Institute of Standards and Technology.

\section{Electrochemical measurements}

The electrodes were prepared by mixing $\mathrm{CF}_{x}$, super $\mathrm{P}$, and a polyvinylidene fluoride (PVDF) binder at a weight ratio of 8:1:1, dispersing the mixture in $N$-methyl pyrrolidone (NMP) to form the homogenous slurry, which was then cast onto $\mathrm{Al}$ foil and vacuum dried at $120^{\circ} \mathrm{C}$ for $12 \mathrm{~h}$. The average mass loading of the active materials was approximately $1-2 \mathrm{mg} \mathrm{cm}^{-2}$. R2032-type coin cells were assembled in a glove box filled with pure Ar gas $\left(\mathrm{O}_{2}\right.$ and $\mathrm{H}_{2} \mathrm{O}$ levels $<0.1 \mathrm{ppm}$ ). Lithium metal was used as the counter electrode and Celgard 2440 was used as the separator. Lithium tetrafluoroborate $\left(\mathrm{LiBF}_{4}\right)\left(1 \mathrm{~mol} \mathrm{~L}^{-1}\right)$ dissolved in propylene carbonate/1,2-dimethoxyethane (PC/DME, 1:1 vol.) was used as the adopted electrolyte. Galvanostatic discharge tests were performed with a cutoff potential of $1.5 \mathrm{~V}\left(v s . \mathrm{Li} / \mathrm{Li}^{+}\right)$at different current densities on a LAND Battery Testing system (CT-2001A). The electrochemical impedance spectrum (EIS) was tested using an electrochemical workstation (PARSTAT
2263; AMETEK SI) at frequencies from $1 \times 10^{6}$ to $0.01 \mathrm{~Hz}$ with a voltage amplitude of $5 \mathrm{mV}$.

\section{RESULTS AND DISCUSSION}

The morphology of the purified SWCNTs was observed by TEM, which indicated that the raw material consisted of macroscopic bundles of SWCNTs with diameters from 10 to $100 \mathrm{~nm}$ with a relatively low level of amorphous carbon and metal particles (Fig. S1a). The corresponding high-resolution TEM (HRTEM) image (Fig. S1b) displayed the long bundles formed by self-agglomeration of the SWCNTs with an average diameter of $1.95 \mathrm{~nm}$. The diffracted rings in the selected area electron diffraction (SAED, inset of Fig. S1) pattern demonstrated the diversity of chirality in the SWCNTs. The TEM images of the fluorinated SWCNTs (Fig. 1) indicated the significant impact of the fluorination temperature on their structure, which agreed with previous studies $[35,36]$. When the fluorination temperature was below $300^{\circ} \mathrm{C}, \mathrm{CF}_{x}$-a (Fig. 1a) and $\mathrm{CF}_{x}$-b (Fig. 1b) approximately retained the original morphology of the SWCNT bundles, and their corresponding HRTEM images (Fig. 1f, g) exhibited the largely intact tubular structure. When the fluorination temperature reached $300^{\circ} \mathrm{C}$, although these fluorinated SWCNTs still aggregated in bundles (Fig. 1c), the HRTEM image of $\mathrm{CF}_{x}$-c (Fig. 1h) indicated the destruction of the tubular structure and the bundles were filled with amorphous fluorinated compounds like fluorinated MWCNTs [37]. With a further increase of the fluorination temperature, it can be observed from the TEM images of $\mathrm{CF}_{x}$-d (Fig. 1d) and $\mathrm{CF}_{x}$-e (Fig. 1e) that the 1D morphology collapsed but some lamellar structures similar to fluorinated graphene were generated. Their corresponding HRTEM images (Fig. 1i, j) further confirmed the complete destruction of the SWCNTs, and the overwhelmingly amorphous structure without any crystalline nanodomains implied the high fluorination degree [25]. Interestingly, the terraced edges in $\mathrm{CF}_{x}-\mathrm{d}$ and $\mathrm{CF}_{x}-\mathrm{e}$ formed by the stacked lamellas indicated probable stripping of the SWCNTs during fluorination. In addition, from the SAED patterns of the prepared $\mathrm{CF}_{x}$ compounds (insets of Fig. 1f-j), the gradually enhanced ambiguous diffracted rings with temperature increase indicated the vigorous structural disorder caused by the oxidative $\mathrm{F}_{2}$ gas.

Due to the notable morphological change of the prepared $\mathrm{CF}_{x}$ at high fluorination temperatures, several TEM images (Fig. S2) of $\mathrm{CF}_{x}$-d, corresponding to different stages during fluorination, were collected to reveal the morphological evolution. The pristine bundles were 

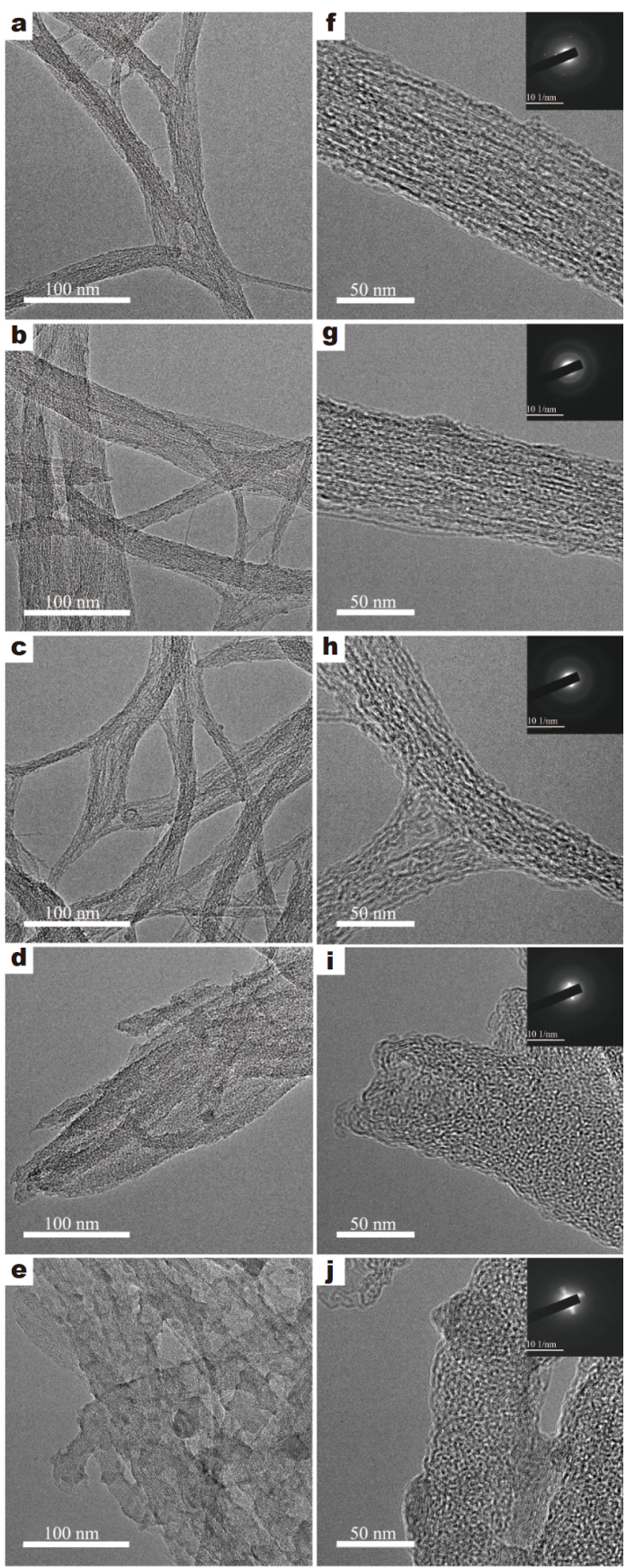

Figure 1 TEM images of $\mathrm{CF}_{x}-\mathrm{a}(\mathrm{a}, \mathrm{f}), \mathrm{CF}_{x}-\mathrm{b}(\mathrm{b}, \mathrm{g}), \mathrm{CF}_{x}-\mathrm{c}(\mathrm{c}, \mathrm{h}), \mathrm{CF}_{x}-\mathrm{d}$ $(\mathrm{d}, \mathrm{i})$, and $\mathrm{CF}_{x}-\mathrm{e}(\mathrm{e}, \mathrm{f})$. The insets in $(\mathrm{f}-\mathrm{j})$ show the corresponding SAED images with a scale bar $101 / \mathrm{nm}$.

tightly constructed by parallel SWCNTs (Fig. S2a). After $10 \mathrm{~min}$ of fluorination, some cracks appeared in the SWCNT bundles (Fig. S2b), which was attributed to the weakened van der Waals attraction and $\pi-\pi$ interactions caused by the surface fluorination. When the fluorination time reached $30 \mathrm{~min}$, fractures appeared in the bundles and the tubular structure became ambiguous (Fig. S2c). After $1 \mathrm{~h}$ of fluorination, the SWCNT bundles separated (Fig. S2d) and the tubular structure was completely destroyed. Further prolonging the fluorination time intensified the structural damage of the SWCNTs (Fig. S2e) and amorphous lamellar structures were observed (Fig. S2f). Therefore, it can be assumed that the initial fluorination outside of the SWCNTs broke the bundles, leading to the penetration of the $\mathrm{F}_{2}$ gas into the internal structure and hence more effective fluorination. Meanwhile, the high reactivity of $\mathrm{F}_{2}$ gas at high temperature likely demolished the tubular structure by generating fluorinated compounds above the stoichiometric limit [38].

AFM images of the SWCNTs and the prepared $\mathrm{CF}_{x}$ compounds were acquired consecutively to investigate their structural configurations. The AFM image of the well-isolated SWCNTs spin-coated on a $\mathrm{SiO}_{2}$ substrate (Fig. S3a) demonstrates large quantities of $1 \mathrm{D}$ bundles with lengths of several micrometers. Their diameters were ascertained by measuring their heights above the substrate and the height distribution (Fig. S3b) was obtained by measuring the height values for approximately hundreds of SWCNTs. The heights of the SWCNTs were mainly distributed at less than $5 \mathrm{~nm}$ with an average height of $3.05 \mathrm{~nm}$. Similarly, the AFM images of $\mathrm{CF}_{x}$-a (Fig. 2a) and $\mathrm{CF}_{x}$-b (Fig. 2b) revealed that the $1 \mathrm{D}$ bundle structure was maintained and the length remained approximately unaltered. In addition, their similar height distributions (Fig. 2f, g) with that of the SWCNTs further confirmed the intact tubular structure when the fluorination temperature was below $300^{\circ} \mathrm{C}$. However, the average heights for $\mathrm{CF}_{x}-\mathrm{a}(3.5 \mathrm{~nm})$ and $\mathrm{CF}_{x}-\mathrm{b}(3.8 \mathrm{~nm})$ were slightly larger than those for the pristine SWCNTs, which was ascribed to the covalently bonded fluorine atoms outside the SWCNT walls [39]. Although the 1D bundle-like structure was still displayed in the AFM image of $\mathrm{CF}_{x}-\mathrm{c}$ (Fig. 2c), the broad or bimodal height distribution (Fig. 2h) indicated partial breakage of the SWCNTs during fluorination that led to the decrease in the heights. When the fluorination was processed at $350^{\circ} \mathrm{C}$, the AFM image of $\mathrm{CF}_{x}-\mathrm{d}$ (Fig. 2d) displayed products with lengths of several micrometers and widths of 20-30 nm, but the height distribution (Fig. 2h) exhibited an average height of only $2.1 \mathrm{~nm}$, which was notably smaller than that of the SWCNTs. Combined with the high length-width ratio alongside the remarkable decrease in apparent height, it can be concluded that the fluorination unzipped the SWCNTs and consequently 
formed F-GNRs, similar to the unzipping process of CNT oxidization [40]. The AFM image of $\mathrm{CF}_{x}$-e (Fig. 2e) demonstrated island-like structures with sizes of several tens of nanometers, which was assigned to the cutting of $\mathrm{F}$ GNRs at their defect sites [41]. The average height obtained from its corresponding height distribution (Fig. 2i) was approximately $1.9 \mathrm{~nm}$, and the close value to that of $\mathrm{CF}_{x}$-d demonstrated that these isolated structures were fragments from F-GNRs at high fluorination temperatures.

Due to the typically lateral dimensions of $\mathrm{CF}_{x}-\mathrm{d}$, it was selected as the reference for analyzing further thickness information. In general, the heights measured by AFM are usually overestimated due to the contributions of capillary forces and adhesion, or even residual solvents. Therefore, the lamellar thickness of $\mathrm{CF}_{x}-\mathrm{d}$ alongside the stacked numbers were determined according to a previous report [42]. The height of the steps across a curved or overlapped $\mathrm{CF}_{x}$-d lamella (Fig. S4a) were measured. From the corresponding plotted AFM heights (Fig. S4b), several steps exhibited similar apparent heights and the step height was always a multiple of $0.9 \mathrm{~nm}$, which is close to the height of monolayer fluorographene and its theoretical thickness [43]. Therefore, it can be concluded that the monolayer F-GNRs were directly obtained by the fluorination of SWCNTs. However, this method is not effective enough to upzip MWCNTs due to the torque energy of MWCNTs are smaller than that of SWCNTs, which can be demonstrated by the TEM image of FMWCNTs (diameters of $20-30 \mathrm{~nm}$, lengths of 2-10 $\mu \mathrm{m}$ ) in Fig. S5.

Raman spectroscopy was used to monitor structural changes of the SWCNTs during fluorination. From Raman spectra (Fig. S6a), the SWCNTs demonstrated characteristic peaks, including well-defined radial breathing modes (RBM) in the region of $170-270 \mathrm{~cm}^{-1}$, a strong and sharp tangential mode at $\sim 1592 \mathrm{~cm}^{-1}$, and a disordered mode with very low intensity at $\sim 1292 \mathrm{~cm}^{-1}$. The prepared $\mathrm{CF}_{x}$ compounds displayed typical D and G bands at approximately 1350 and $1590 \mathrm{~cm}^{-1}$, respectively. The gradually broadened and augmented intensity of the $\mathrm{D}$ band at $1350 \mathrm{~cm}^{-1}$ in $\mathrm{CF}_{x}$ with increasing fluorination temperature corresponded to the intensified disordered mode. The calculated ratios of the $\mathrm{D}$ band $\left(\sim 1350 \mathrm{~cm}^{-1}\right)$ to $\mathrm{G}$ band $\left(\sim 1590 \mathrm{~cm}^{-1}\right)$ intensities $\left(I_{\mathrm{D}} / I_{\mathrm{G}}\right)$ of $\mathrm{CF}_{x^{-}} \mathrm{a}, \mathrm{CF}_{x^{-}}$ $\mathrm{b}$, and $\mathrm{CF}_{x}-\mathrm{c}$ were $0.82,1.17$, and 1.23 , respectively, indicating the decreased amount of $\mathrm{sp}^{2}$ domains. However, the Raman peaks for $\mathrm{CF}_{x}-\mathrm{d}$ and $\mathrm{CF}_{x}$-e were very weak and broad, which was potentially attributed to the higher content of $\mathrm{sp}^{3}$ hybridized carbons in the structure due to
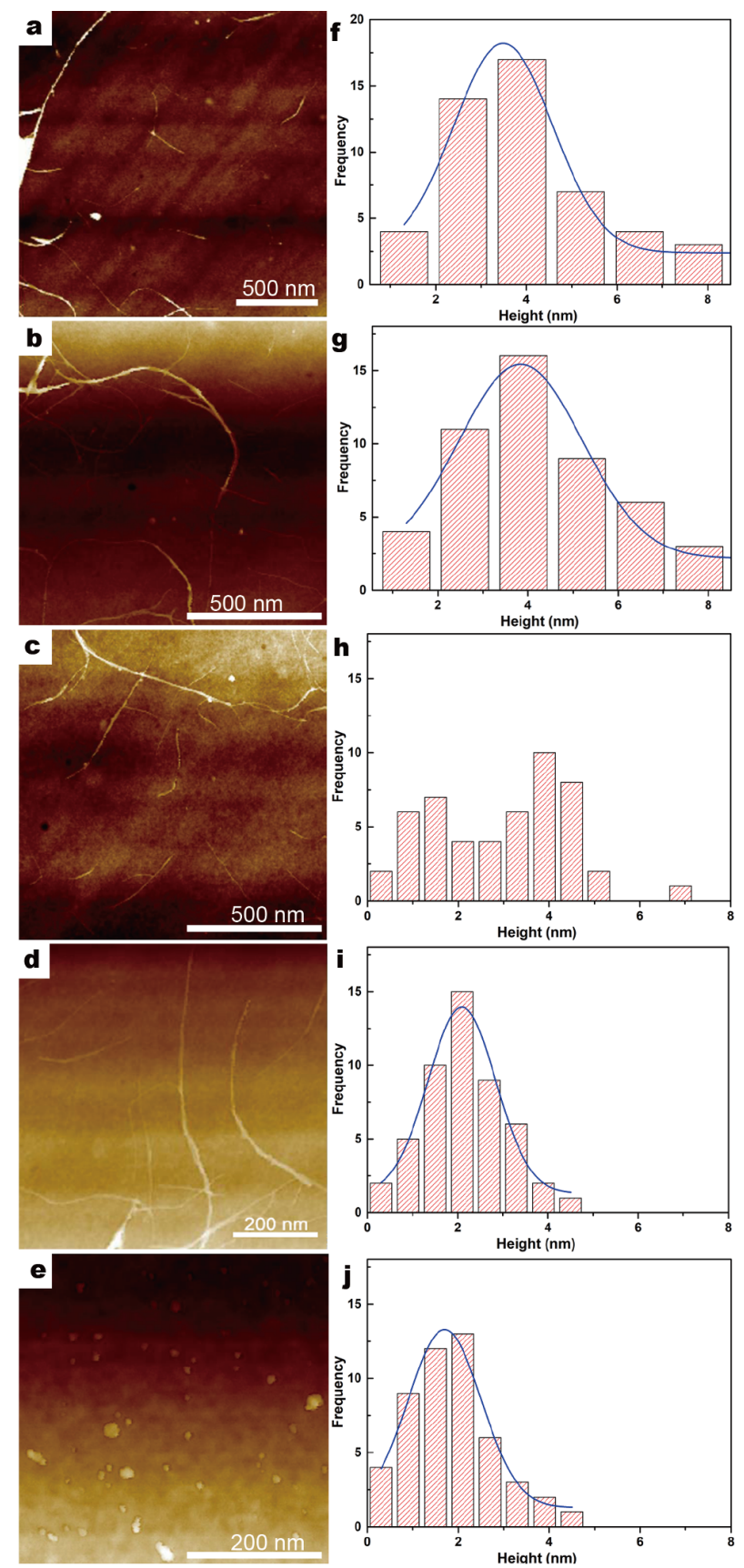

Figure 2 Morphological characterization of of $\mathrm{CF}_{x}$ by AFM. (a-e) AFM and ( $f-j)$ height distribution analyses of the AFM images of $(a, f)$ $\mathrm{CF}_{x}-\mathrm{a},(\mathrm{b}, \mathrm{g}) \mathrm{CF}_{x}-\mathrm{b},(\mathrm{c}, \mathrm{h}) \mathrm{CF}_{x}-\mathrm{c},(\mathrm{d}, \mathrm{i}) \mathrm{CF}_{x}-\mathrm{d}$ and $(e, j) \mathrm{CF}_{x}-\mathrm{e}$.

the intensive fluorination process. FTIR spectra were obtained (Fig. S6b) to determine the change of the functional groups during fluorination. The stretching vibrational mode of $\mathrm{C}=\mathrm{C}$ (aromatic) at $1530 \mathrm{~cm}^{-1}$ and the $\mathrm{C}-\mathrm{F}$ bonds at $1212 \mathrm{~cm}^{-1}$ were observed in the spectra of all of the prepared $\mathrm{CF}_{x}$ compounds. The signal of the 
$\mathrm{C}=\mathrm{C}$ bond gradually disappeared with the increase of fluorination temperature, indicating that the structure of the SWCNTs was gradually destroyed, which was consistent with their TEM images. The crystal structures of the SWCNTs and the prepared $\mathrm{CF}_{x}$ compounds were characterized by XRD (Fig. S6c). Only one diffraction peak, centered at $24.0^{\circ}$, was observed in the SWCNT patterns, which was assigned to the (002) reflection, corresponding to the interlayer spacing of the carbon sheets. The shift of the diffraction peaks in the $\mathrm{CF}_{x}$ compounds to lower angles indicated the enlarged spacing distance of the (002) crystal planes after fluorination, but the markedly reduced intensity and broadened width implied the loss of interlayer correlations between the fluorinated carbon layers. However, $\mathrm{CF}_{x}-\mathrm{d}$ and $\mathrm{CF}_{x}-\mathrm{e}$ exhibited two diffraction peaks at approximately $13.5^{\circ}$ and $24^{\circ}$, which was consistent with the diffraction pattern of fluorinated graphene. The reflection at $13.5^{\circ}$ could be assigned to the (001) reflection of a hexagonal crystal structure, particularly for compounds with high fluorine content.

Subsequently, the composition and fluorinated species of the prepared $\mathrm{CF}_{x}$ compounds were identified by XPS survey spectra (Fig. S7), and the extensive F 1s signals demonstrated the effective fluorination of the SWCNTs. The elemental contents in the prepared $\mathrm{CF}_{x}$ compounds are listed in Table S1 and the elemental mapping of the selected $\mathrm{CF}_{x}-\mathrm{d}$ (Fig. S8) further confirmed the homogeneous distribution of fluorination. The high-resolution $\mathrm{C}$ 1s spectra of the SWCNTs and prepared $\mathrm{CF}_{x}$ compounds (Fig. S9) confirmed the formation of fluorinated species with various compositions and conformations, and their contents are also listed in Table S1. The peaks at 284.8 and $285.9 \mathrm{eV}$ were assigned to the $\mathrm{sp}^{2} \mathrm{C}=\mathrm{C}$ bonds and $\mathrm{sp}^{3} \mathrm{C}-\mathrm{CF}$ bonds, respectively. Four peaks were also observed at 289.0,289.9, 292.0, and $293.6 \mathrm{eV}$, which were ascribed to a semi-ionic $\mathrm{C}-\mathrm{F}$ bond, covalent $\mathrm{C}-\mathrm{F}$ bonds in $-\mathrm{FC}(\mathrm{CF})_{3},-\mathrm{CF}_{2}$, and $-\mathrm{CF}_{3}$ groups, respectively. It should be noted that the fluorine to carbon $(\mathrm{F} / \mathrm{C})$ molar ratios of $\mathrm{CF}_{x}-\mathrm{d}$ (1.15) and $\mathrm{CF}_{x}$-e (1.21) were higher than that of stoichiometric carbon monofluoride. Based on the morphological analysis, the unzipping of the SWCNTs by $\mathrm{F}_{2}$ gas at high temperature led to the formation of F-GNRs, and the abundant edges facilitated the fluorination process and consequently generated perfluorinated groups. Their high F/C ratios implied low concentrations of isolated $\mathrm{C}$ atoms without fluorinated neighbor species, $\mathrm{CF}_{2}$ group, can keep the structure stable. Moreover, it can be noted that the amount of $-\mathrm{CF}_{3}$ groups increased with increasing fluorination temperatures, which indicates that the further fluorination of the F-GNRs broke the C-C bonds and subsequently formed $-\mathrm{CF}_{3}$ groups and even gaseous carbon fluorides. The corresponding high resolution $\mathrm{F}$ 1s spectra for the prepared $\mathrm{CF}_{x}$ compounds (Fig. S10) were used to further investigate the fluorinated species. The concentrations of each fluorinated component, listed in Table S1, agreed with the C 1s spectra results.

The fluorination of the SWCNTs above $300^{\circ} \mathrm{C}$ induced the unzipping of the SWCNTs that formed F-GNRs, and therefore theoretical calculations were performed to understand the reaction mechanism of the fluorine addition path on both the armchair and zigzag SWCNTs. Initially, an ideal $(6,6)$ arm chair SWCNT was constructed using periodic boundary conditions to analyze the addition of fluorinated patterns. The adsorption energy of $\mathrm{F}_{2}$ over the armchair SWCNT is $-0.97 \mathrm{eV}$ with a negligible dissociation barrier $(0.03 \mathrm{eV})$ of two individual $\mathrm{F}$ atoms, indicating the easy dissociation of $\mathrm{F}_{2}$. The first $\mathrm{F}$ atom is randomly attached onto position 1 (Fig. S11), and the corresponding deformation charge density (Fig. 3a) demonstrates a modest deshielding effect on the adjacent $\beta$ carbon, compared with the hydrogenation process [44]. All of the possible adsorption positions for the second $\mathrm{F}$ atom were tested to guarantee the local minimum energy, and the adsorption energy values for different structures (Fig. S12) are listed in Table S2. It was found that the additional $\mathrm{F}$ adsorption energies over the positively charged $2^{\prime}, 2$, and 4 sites were higher than the energies over the negatively charged 3 and 6 sites. This demonstrates that the first two $\mathrm{F}$ atoms were inclined to follow the $1,2^{\prime}$ addition pattern and the preferential $\mathrm{F}$ addition position was dependent on the charge population after one $\mathrm{F}$ atom was stuck on the SWCNT. The calculated energy values of the different positions for the third $\mathrm{F}$ atom addition (Fig. S13) are listed in Table S3. Similarly, it is determined that the addition of $\mathrm{F}$ atoms on the 2 position generated the structure with the lowest adsorption energy. Furthermore, the adsorption energy for the fourth $\mathrm{F}$ atom on the 2 position (Fig. S14) showed the lowest energy value (Table S4). The calculation of the initial four F atoms adsorbed on the SWCNTs indicates that the fluorination reacted by 1,2 ' addition, so that the next four $\mathrm{F}$ atoms were assumed to be added onto the SWCNTs according to the same pathway (Fig. 3b). The Gibbs free energy of this structure before and after unzipping was calculated. The gradually reduced relative Gibbs free energy demonstrates that the unzipping process of the SWCNT during fluorination was spontaneous (Fig. 3c). Finally, the structure of Fig. 3b after unzipping 

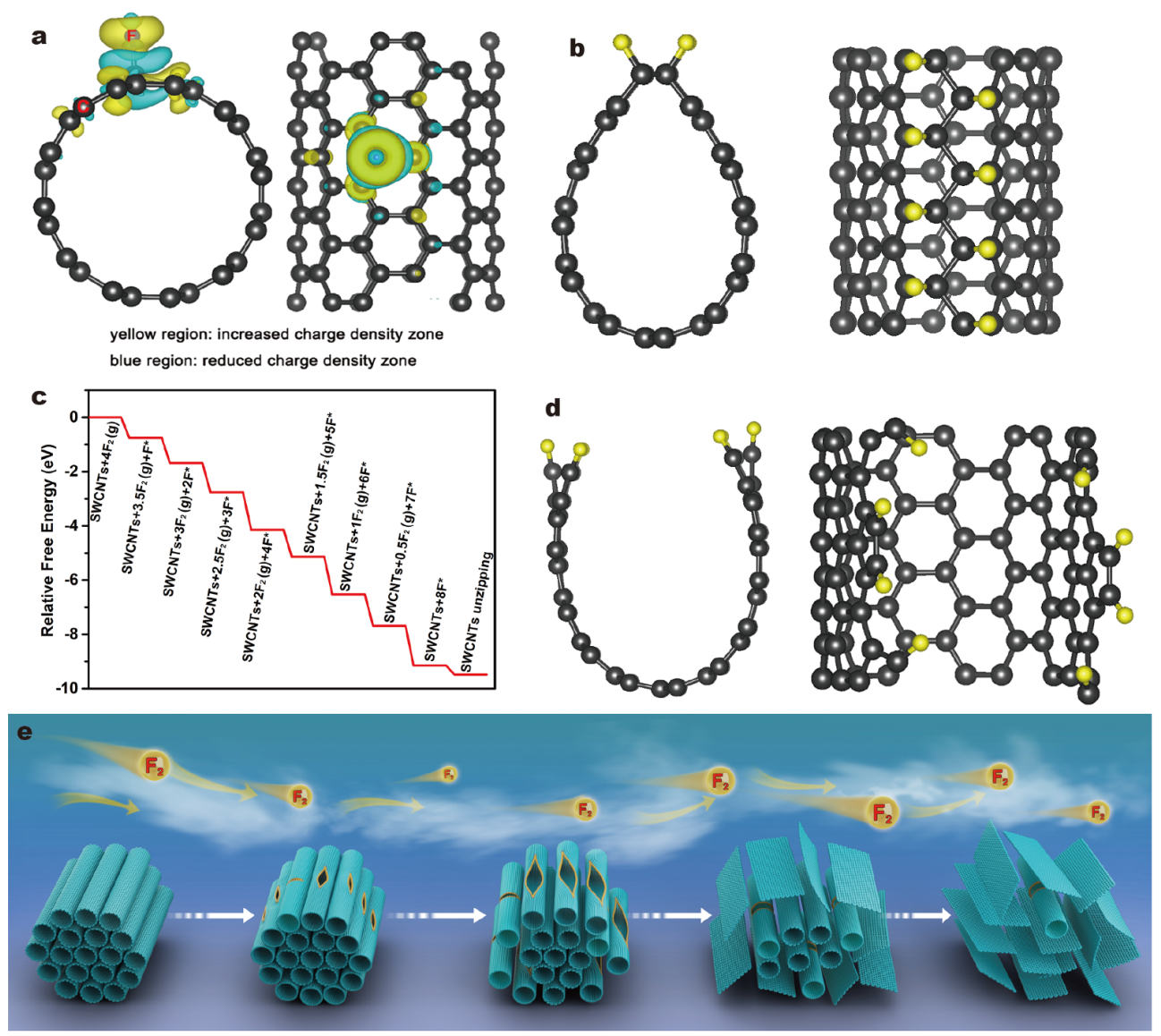

Figure 3 (a) Deformation charge density of SWCNT after the addition of a fluorine atom; (b) the structure of the first eight fluorine atoms addition; (c) the change of Gibbs free energy during unzipping process of SWCNT caused by F addition; (d) the structure of SWCNT after unzipping; (e) representation of the gradual unzipping of single-walled carbon nanotubes to form fluorinated graphene nanoribbons. Fluorinated sites are not shown.

is shown in Fig. 3d. The additional $\mathrm{F}$ atoms were introduced to the unzipped edges to obtain the final stable structure for further fluorination (Fig. S15), which reflected the abundance of perfluorinated groups in the FGNRs. Similarly, the fluorination pathway for an ideal $(6,6)$ zigzag SWCNT was also performed. The calculated adsorption energies for the possible configurations of the addition sites for the initial two F atoms on the SWCNT (Fig. S16) are listed in Table S5, and it can be noted that the fluorination for the zigzag SWCNT was still in accordance with the 1,2' addition mode. Therefore, it was reasonable to deduce that the zigzag SWCNTs are likely to be cut into short fragments (Fig. S17). Therefore, a schematic fluorination of SWCNTs at high temperatures was proposed (Fig. 3e). The early stage of fluorination of the SWCNTs through the zigzag pathway caused inner strains that initiated tearing of the SWCNTs. The SWCNTs were gradually unzipped to form F-GNRs. It should be noted that the SWCNT bundles were mixtures of various chiralities and hence the direction of unzipping of the SWCNTs was random, illustrated by the branches and fragments in the TEM images.

The galvanostatic discharge profiles of the prepared $\mathrm{CF}_{x}$ used as the cathodes of lithium primary batteries at different current densities (Fig. 4a-e) demonstrated the typical two-phase nature of the discharge reaction with stable plateaus [45]. It should be noted that the discharge plateaus of all of the prepared $\mathrm{CF}_{x}$ were approximately $3.0 \mathrm{~V}\left(v s . \mathrm{Li} / \mathrm{Li}^{+}\right)$at a current density of $10 \mathrm{~mA} \mathrm{~g}^{-1}$, higher than that of conventional graphite fluorides $(\sim 2.6 \mathrm{~V} v s$. $\left.\mathrm{Li} / \mathrm{Li}^{+}\right)$. The increased discharge plateaus of the $\mathrm{CF}_{x}$ fluorinated at temperatures below $300^{\circ} \mathrm{C}$ were attributed to the semi-ionic $\mathrm{C}-\mathrm{F}$ bond and the remaining conjugated structure [46]. On the other hand, the high discharge plateaus of the $\mathrm{CF}_{x}$ fluorinated above $300^{\circ} \mathrm{C}$, with high $\mathrm{F} / \mathrm{C}$ ratios, were assigned to the destroyed periodic 

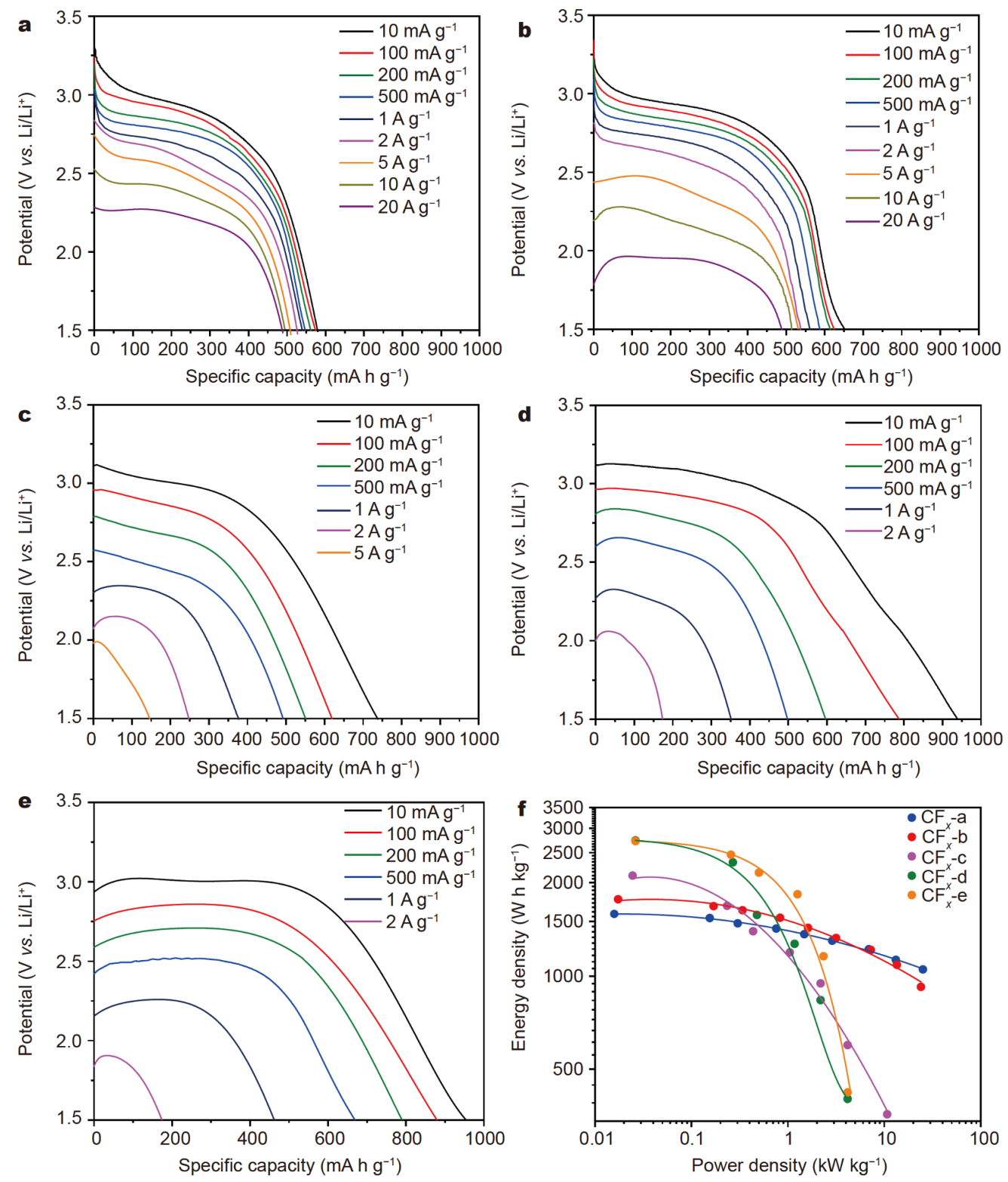

Figure 4 The galvanostatic discharge curves at different discharge rates of (a) $\mathrm{CF}_{x}-\mathrm{a},(\mathrm{b}) \mathrm{CF}_{x}-\mathrm{b},(\mathrm{c}) \mathrm{CF}_{x}-\mathrm{c},(\mathrm{d}) \mathrm{CF}_{x}-\mathrm{d}$, and (e) $\mathrm{CF}_{x}$-e. (f) Ragone plot of $\mathrm{Li} / \mathrm{CF}_{x}$ batteries with different $\mathrm{CF}_{x}$ cathodes.

structures in the F-GNRs according to our previous proposal [19], although the discharge plateau of $\mathrm{CF}_{x}-\mathrm{e}$ was slightly lower than $3.0 \mathrm{~V}\left(v s . \mathrm{Li} / \mathrm{Li}^{+}\right)$due to the reduced electrochemical activity of the perfluorinated groups [21]. The specific capacities of the prepared $\mathrm{CF}_{x}$ obtained at $10 \mathrm{~mA} \mathrm{~g}^{-1}$ are listed in Table S6, which are close to the theoretical values determined by the $\mathrm{F} / \mathrm{C}$ ratios from the XPS survey profiles.

However, the specific capacities for $\mathrm{CF}_{x}-\mathrm{d}$ and $\mathrm{CF}_{x}-\mathrm{e}$ cathodes were slightly larger than their theoretical values, which was caused by the abundant defects in the unzipped F-GNRs, such as edges and vacancies, that adsorbed extra $\mathrm{Li}^{+}$ions during the reduction of the $\mathrm{CF}_{x}$ cathodes. With the increase in current density, the discharge plateaus for all of the $\mathrm{CF}_{x}$ cathodes decreased due to the polarization. However, the capacity retentions for the $\mathrm{CF}_{x}$ cathodes fluorinated below $300^{\circ} \mathrm{C}$ were much higher than those obtained at high fluorination temperatures. When the current density was $2 \mathrm{~A} \mathrm{~g}^{-1}$, the specific capacities of $\mathrm{CF}_{x}$-a and $\mathrm{CF}_{x}$-b reduced slightly to 
525.94 and $536.63 \mathrm{~mA} \mathrm{~h} \mathrm{~g}^{-1}$, while the specific capacities for $\mathrm{CF}_{x}-\mathrm{c}, \mathrm{CF}_{x}-\mathrm{d}$ and $\mathrm{CF}_{x}$-e were only 247.15, 173.46, and $174.12 \mathrm{~mA} \mathrm{~h} \mathrm{~g}^{-1}$. The former two $\mathrm{CF}_{x}$ cathodes delivered specific capacities of $85.32 \%$ and $80.71 \%$ of their theoretical values even at a current density of $10 \mathrm{~A} \mathrm{~g}^{-1}$. The excellent rate capabilities were also endowed by the electronic, conductive, semi-ionic C-F bonds and conjugated structure, alongside the 1D nanostructure for the carriers transportation [47].

The inferior rate capabilities of the $\mathrm{CF}_{x}$ cathodes prepared at high fluorination temperatures were ascribed to the destroyed conjugated structure due to their high fluorination degrees. The charge-transfer resistance $\left(R_{\mathrm{ct}}\right)$ revealed by the Nyquist plots of the fresh $\mathrm{CF}_{x}$ cathodes at open-circuit potentials (Fig. S18) further proved their rate capabilities, and the value of $R_{\mathrm{ct}}$ was enlarged significantly at high fluorination temperatures. Ragone plots of the prepared $\mathrm{CF}_{x}$ cathodes (Fig. 4f) were performed to compare their electrochemical performances. At low current densities, the $\mathrm{CF}_{x}$ cathodes prepared at fluorination temperatures above $300^{\circ} \mathrm{C}$ exhibited superior energy densities. The maximum energy density of $\mathrm{CF}_{x}-\mathrm{d}$ was $2738.45 \mathrm{~W} \mathrm{~h} \mathrm{~kg}^{-1}$ due to its high specific capacity and a discharge plateau above $3.0 \mathrm{~V}\left(v s . \mathrm{Li} / \mathrm{Li}^{+}\right)$, which was higher than most of the $\mathrm{CF}_{x}$ reported in the literature [19-22]. The increase in the discharge current density leads to the decrease in the energy density of the $\mathrm{CF}_{x}$ cathode due to the drop in the operational potential and specific capacity. As expected, the $\mathrm{CF}_{x}$ cathodes fluorinated at relatively low temperatures, associated with the semi-ionic C-F bonds, exhibited remarkable power densities. The maximum power density was delivered by $\mathrm{CF}_{x}$ a at $20 \mathrm{~A} \mathrm{~g}^{-1}$, which was comparable to recently reported nanostructure $\mathrm{CF}_{x}$ compounds $[26,48,49]$. Therefore, this study confirms the excellent maneuverability of SWCNTs as ideal starting materials for $\mathrm{CF}_{x}$ compounds, which can be used in different applications that require high energy or power densities. Moreover, it should be announced that the energy density of $\mathrm{CF}_{x}-\mathrm{d}$, unzipped from the SWCNTs during fluorination, exceeded the theoretical energy densities of typical lithium primary batteries and other approaches for improving the delivered energy densities of many metal-gas batteries (Fig. 5), aside from the $\mathrm{Li}-\mathrm{O}_{2}$ battery operated at $150^{\circ} \mathrm{C}$ that took advantage of the $4 \mathrm{e}^{-}$reaction [50]. Considering the electrode reaction and battery configuration, the high energy density of the F-GNRs provided feasible practicability for military or space applications, and further surface modifications will compensate for the inferior rate capability without the loss of energy density.

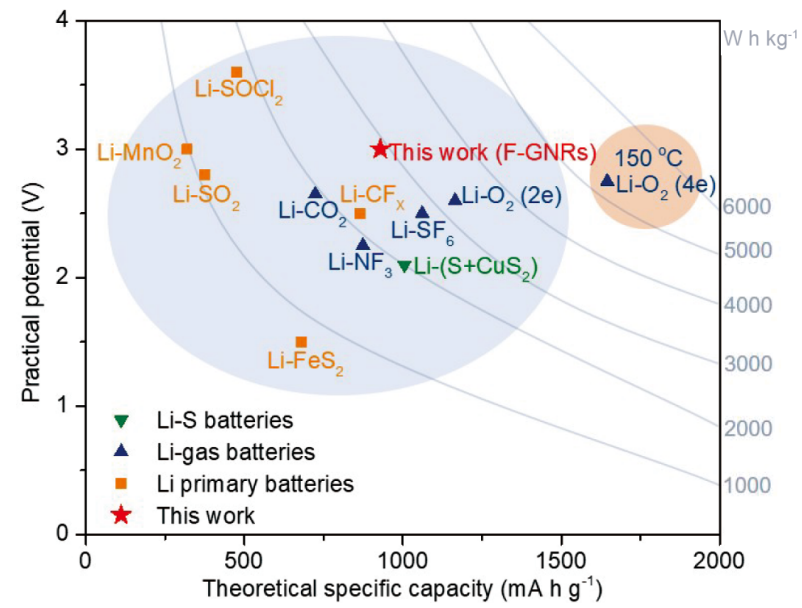

Figure 5 Practical and theoretical specific capacities and energy densities of Li primary batteries, $\mathrm{Li}-\mathrm{S}$, and Li-gas batteries and comparison with the practical values for the Li-(F-GNRs) battery obtained in this study.

\section{CONCLUSIONS}

In summary, by adjusting the fluorination conditions, the unzipping of SWCNTs was realized that led to the formation of F-GNRs when the fluorination temperature exceeded $300^{\circ} \mathrm{C}$. DFT calculations revealed that the addition of $\mathrm{F}$ atoms onto SWCNT was in accordance with a zigzag pathway and the reduced Gibbs free energy confirmed the spontaneous process of unzipping SWCNTs at this fluorination temperature. Based on various morphological and structural characterizations, the prepared $\mathrm{CF}_{x}$ compounds with the retained tubular structure exhibited an F/C ratio of approximately 0.5 and abundant semi-ionic C-F bonds; the unzipped, amorphous, monolayer F-GNRs demonstrated a high F/C ratio with evident perfluorinated groups at the unzipped edges. The high F/C ratio of the F-GNRs guaranteed the high specific capacity of $939.2 \mathrm{~mA} \mathrm{~h} \mathrm{~g}^{-1}$, accompanied by some capacity derived from $\mathrm{Li}^{+}$adsorption on the defective sites, and the destroyed periodic structure induced the high discharge potential of approximately $3.0 \mathrm{~V}\left(v s . \mathrm{Li} / \mathrm{Li}^{+}\right)$. The optimized F-GNRs by unzipping the SWCNTs at $350^{\circ} \mathrm{C}$ exhibited the maximum energy density of $2738.45 \mathrm{~W} \mathrm{~h} \mathrm{~kg}^{-1}$. It is hoped that further surface modification of the F-GNRs will improve their rate capability so as to realize their practical application in lithium primary batteries for ultrahigh-energy-density devices.

\section{Received 12 September 2020; accepted 28 October 2020; published online 21 January 2021}

1 Krause FC, Jones JP, Jones SC, et al. High specific energy lithium 
primary batteries as power sources for deep space exploration. J Electrochem Soc, 2018, 165: A2312-A2320

2 Zhang T, Li Z, Hou W, et al. Nanomaterials for implantable batteries to power cardiac devices. Mater Today Nano, 2020, 9: 100070

3 Zhang Q, Takeuchi KJ, Takeuchi ES, et al. Progress towards highpower $\mathrm{Li} / \mathrm{CF}_{x}$ batteries: electrode architectures using carbon nanotubes with $\mathrm{CF}_{\mathrm{x}}$. Phys Chem Chem Phys, 2015, 17: 22504-22518

4 Choi JW, Aurbach D. Promise and reality of post-lithium-ion batteries with high energy densities. Nat Rev Mater, 2016, 1: 16013

5 Hartmann P, Bender CL, Vračar M, et al. A rechargeable roomtemperature sodium superoxide $\left(\mathrm{NaO}_{2}\right)$ battery. Nat Mater, 2013, 12: $228-232$

6 Ren $\mathrm{X}, \mathrm{Wu}$ Y. A low-overpotential potassium-oxygen battery based on potassium superoxide. J Am Chem Soc, 2013, 135: 29232926

7 Zhang Z, Zhang Q, Chen Y, et al. The first introduction of graphene to rechargeable $\mathrm{Li}-\mathrm{CO}_{2}$ batteries. Angew Chem Int Ed, 2015, 54: 6550-6553

8 Qiao Y, Yi J, Wu S, et al. Li-CO $\mathrm{CO}_{2}$ electrochemistry: A new strategy for $\mathrm{CO}_{2}$ fixation and energy storage. Joule, 2017, 1: 359-370

9 He M, Li Y, Guo R, et al. Electrochemical conversion of nitrogen trifluoride as a gas-to-solid cathode in Li batteries. J Phys Chem Lett, 2018, 9: 4700-4706

10 Li Y, Khurram A, Gallant BM. A high-capacity lithium-gas battery based on sulfur fluoride conversion. J Phys Chem C, 2018, 122: 7128-7138

11 Gao H, Li Y, Guo R, et al. Controlling fluoride-forming reactions for improved rate capability in lithium-perfluorinated gas conversion batteries. Adv Energy Mater, 2019, 9: 1900393

$12 \mathrm{He} \mathrm{H}$, Ren F, Zhu J, et al. Highly-efficient conversion of $\mathrm{SF}_{6}$ via an eight-electron transfer process in lithium batteries. Nano Energy, 2020, 72: 104679

13 Ma Y, Zhang $\mathrm{H}, \mathrm{Wu} \mathrm{B}$, et al. Lithium sulfur primary battery with super high energy density: based on the cauliflower-like structured C/S cathode. Sci Rep, 2015, 5: 14949

14 Cheng JJ, Liu LF, Ou SW, et al. Sulfur/ $\mathrm{Cu}_{x} \mathrm{~S}$ hybrid material for Li/ $\mathrm{S}$ primary battery with improved discharge capacity. Mater Chem Phys, 2019, 224: 384-388

15 Zhan L, Song Z, Shan N, et al. Poly(tetrahydrobenzodithiophene): High discharge specific capacity as cathode material for lithium batteries. J Power Sources, 2009, 193: 859-863

$16 \mathrm{Lu} \mathrm{Y}$, Hou X, Miao L, et al. Cyclohexanehexone with ultrahigh capacity as cathode materials for lithium-ion batteries. Angew Chem Int Ed, 2019, 58: 7020-7024

17 Sun $\mathrm{P}, \mathrm{Bai} \mathrm{P}, \mathrm{Chen} \mathrm{Z}$, et al. A lithium-organic primary battery. Small, 2020, 16: 1906462

18 Jones JP, Jones SC, Billings KJ, et al. Radiation effects on lithium $\mathrm{CF}_{x}$ batteries for future spacecraft and landers. J Power Sources, 2020, 471: 228464

19 Peng C, Li Y, Yao F, et al. Ultrahigh-energy-density fluorinated calcinated macadamia nut shell cathodes for lithium/fluorinated carbon batteries. Carbon, 2019, 153: 783-791

20 Zhou R, Li Y, Feng Y, et al. The electrochemical performances of fluorinated hard carbon as the cathode of lithium primary batteries. Compos Commun, 2020, 21: 100396

21 Ahmad Y, Dubois M, Guérin K, et al. Pushing the theoretical limit of $\mathrm{Li}-\mathrm{CF}_{x}$ batteries using fluorinated nanostructured carbon nanodiscs. Carbon, 2015, 94: 1061-1070

22 Ahmad Y, Dubois M, Guerin K, et al. High energy density of primary lithium batteries working with sub-fluorinated few walled carbon nanotubes cathode. J Alloys Compd, 2017, 726: 852-859

23 Read J, Collins E, Piekarski B, et al. LiF formation and cathode swelling in the Li/CF ${ }_{x}$ battery. J Electrochem Soc, 2011, 158: A504

24 Feng W, Long P, Feng Y, et al. Two-dimensional fluorinated graphene: synthesis, structures, properties and applications. Adv Sci, 2016, 3: 1500413

25 Sun C, Feng Y, Li Y, et al. Solvothermally exfoliated fluorographene for high-performance lithium primary batteries. Nanoscale, 2014, 6: 2634-2641

26 Zhong G, Chen H, Huang X, et al. High-power-density, highenergy-density fluorinated graphene for primary lithium batteries. Front Chem, 2018, 6: 50

27 Jiao L, Zhang L, Wang X, et al. Narrow graphene nanoribbons from carbon nanotubes. Nature, 2009, 458: 877-880

28 Rzeszotarski B, Mreńca-Kolasińska A, Szafran B. Electron spin inversion in fluorinated graphene nanoribbons. Phys Rev B, 2017, 96: 245307

29 Nguyen DK, Lin YT, Lin SY, et al. Fluorination-enriched electronic and magnetic properties in graphene nanoribbons. Phys Chem Chem Phys, 2017, 19: 20667-20676

30 Romero Aburto R, Alemany LB, Weldeghiorghis TK, et al. Chemical makeup and hydrophilic behavior of graphene oxide nanoribbons after low-temperature fluorination. ACS Nano, 2015, 9: 7009-7018

31 Yang Z, Liu M, Zhang C, et al. Carbon nanotubes bridged with graphene nanoribbons and their use in high-efficiency dye-sensitized solar cells. Angew Chem Int Ed, 2013, 52: 3996-3999

32 Perdew JP, Burke K, Ernzerhof M. Generalized gradient approximation made simple. Phys Rev Lett, 1996, 77: 3865-3868

33 Blöchl PE. Projector augmented-wave method. Phys Rev B, 1994, 50: $17953-17979$

34 Monkhorst HJ, Pack JD. Special points for Brillouin-zone integrations. Phys Rev B, 1976, 13: 5188-5192

35 Mickelson ET, Huffman CB, Rinzler AG, et al. Fluorination of single-wall carbon nanotubes. Chem Phys Lett, 1998, 296: 188-194

36 Lee YS, Cho TH, Lee BK, et al. Surface properties of fluorinated single-walled carbon nanotubes. J Fluorine Chem, 2003, 120: 99104

37 Li Y, Feng Y, Feng W. Deeply fluorinated multi-wall carbon nanotubes for high energy and power densities lithium/carbon fluorides battery. Electrochim Acta, 2013, 107: 343-349

38 Park KA, Choi YS, Lee YH, et al. Atomic and electronic structures of fluorinated single-walled carbon nanotubes. Phys Rev B, 2003, 68: 045429

39 Marcoux PR, Schreiber J, Batail P, et al. A spectroscopic study of the fluorination and defluorination reactions on single-walled carbon nanotubes. Phys Chem Chem Phys, 2002, 4: 2278-2285

40 Jiao L, Wang X, Diankov G, et al. Facile synthesis of high-quality graphene nanoribbons. Nat Nanotech, 2010, 5: 321-325

41 Gu Z, Peng H, Hauge RH, et al. Cutting single-wall carbon nanotubes through fluorination. Nano Lett, 2002, 2: 1009-1013

42 Zhang $\mathrm{P}$, Zhao F, Long P, et al. Sonication-assisted liquid-phase exfoliated $\alpha$-GeTe: a two-dimensional material with high $\mathrm{Fe}^{3+}$ sensitivity. Nanoscale, 2018, 10: 15989-15997

43 Zbořil R, Karlický F, Bourlinos AB, et al. Graphene fluoride: A stable stoichiometric graphene derivative and its chemical conversion to graphene. Small, 2010, 6: 2885-2891

44 Alemany LB, Zhang L, Zeng L, et al. Solid-state NMR analysis of fluorinated single-walled carbon nanotubes: assessing the extent of fluorination. Chem Mater, 2007, 19: 735-744 
Zhang SS, Foster D, Wolfenstine J, et al. Electrochemical characteristic and discharge mechanism of a primary $\mathrm{Li} / \mathrm{CF}_{x}$ cell. J Power Sources, 2009, 187: 233-237

46

Giraudet J, Delabarre C, Guérin K, et al. Comparative performances for primary lithium batteries of some covalent and semicovalent graphite fluorides. J Power Sources, 2005, 158: 1365-1372 Yazami R, Hamwi A, Guérin K, et al. Fluorinated carbon nanofibres for high energy and high power densities primary lithium batteries. Electrochem Commun, 2007, 9: 1850-1855

48 Dai Y, Fang Y, Cai S, et al. Surface modified pinecone shaped hierarchical structure fluorinated mesocarbon microbeads for ultrafast discharge and improved electrochemical performances. J Electrochem Soc, 2017, 164: A1-A7

49 Wang L, Li Y, Wang S, et al. Fluorinated nanographite as a cathode material for lithium primary batteries. ChemElectroChem, 2019, 6: 2201-2207

50 Xia C, Kwok CY, Nazar LF. A high-energy-density lithium-oxygen battery based on a reversible four-electron conversion to lithium oxide. Science, 2018, 361: 777-781

Acknowledgements This work was financially supported by the National Key R\&D Program of China (2016YFA0202302), the State Key Program of National Natural Science Foundation of China (51633007), and the National Natural Science Foundation of China (51773147, 51803149 and 51973151).

Author contributions The manuscript was written through contributions of all authors. All authors have given approval to the final version of the manuscript.

Conflict of interest The authors declare no conflict of interest.

Supplementary information online version of the paper.

Supporting data are available in the

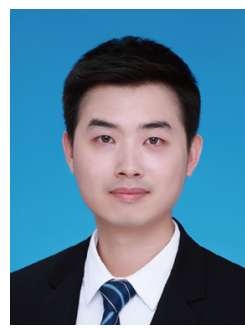

Cong Peng obtained his MSc degree from Hubei University in 2016. He is currently working on his $\mathrm{PhD}$ in Professor Feng's group at the School of Materials Science and Engineering in Tianjin University. His research interests include the synthesis, assemblies, and application of fluorinated carbon materials.

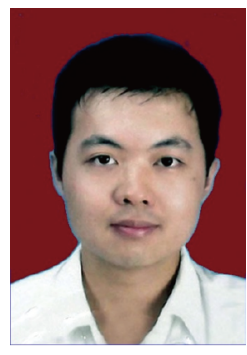

Yu Li is a lecturer at the School of Materials Science and Engineering, Tianjin University. He obtained his $\mathrm{PhD}$ degree from Tianjin University in 2011 and had worked as a postdoctoral research fellow at Tianjin University from 2011 to 2014. His current research is focused on conductive polymers and nano energy storage materials.

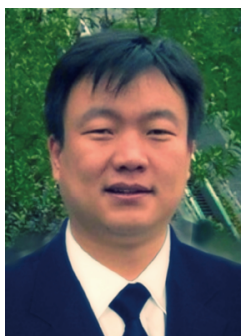

Wei Feng received his $\mathrm{PhD}$ in 2000 from Xi'an Jiaotong University focusing on photoelectric properties and device applications of novel conducting polymers. Then he worked at Osaka University and Tsinghua University as a JSPS fellow and postdoctoral researcher, respectively. In 2004, he became a full professor at Tianjin University. His research interest is the functional nanocarbon materials.

\section{切割单壁碳纳米管制备氟化石墨烯纳米带应用于 超高能量密度理-氟化碳电池}

彭聪, 孔令辰, 李㻦 ${ }^{*}$, 付浩宇, 孙立东, 冯奕钜, 封伟 ${ }^{*}$

摘要 由于 $\mathrm{CF}_{x}$ 正极材料的优势, 锂-氟化碳 $\left(\mathrm{Li}-\mathrm{CF}_{x}\right)$ 电池已成为一 种应用广泛、能提供巨大能量密度的电源之一. 但其实际放电电 压与理论放电电压之间的较大差距, 以及商用氟化石墨的化学计 量极限, 使得进一步提高其能量密度面临挑战. 本文采用纯 $\mathrm{F}_{2}$ 气体 直接在高温下对单壁碳纳米管(SWCNTs)进行切割, 制备出单层氟 化石墨烯纳米带(F-GNRs). 丰富的边缘结构和碳骨架周期性结构 的破坏使其具有高的氟化程度和放电平台, 从而使其能量密度高 达2738.45 W h kg . 理论计算表明在高氟化温度下, 氟原子在碳纳 米管外以zigzag路径吸附, 进一步证实了切割单壁碳纳米管形成单 层F-GNRs为自发过程. 单壁碳纳米管的可控氟化为制备具有不同 用途的 $\mathrm{CF}_{x}$, 特别是具有超高能量密度正极材料提供了一条可行途 径. 